\title{
Acromegaly: the disease, its impact on patients, and managing the burden of long-term treatment
}

This article was published in the following Dove Press journal:

International Journal of General Medicine

17 January 2013

Number of times this article has been viewed

\author{
Daphne T Adelman' \\ Karen JP Liebert ${ }^{2}$ \\ Lisa B Nachtigall ${ }^{2}$ \\ Michele Lamerson ${ }^{3}$ \\ Bert Bakker ${ }^{3}$ \\ 'Division of Endocrinology, \\ Metabolism and Molecular Medicine, \\ Feinberg School of Medicine, \\ Northwestern University, Chicago, IL, \\ ${ }^{2}$ Neuroendocrine Unit, Massachusetts \\ General Hospital, Boston, MA, \\ ${ }^{3}$ Endocrinology Medical Affairs, Ipsen \\ Biopharmaceuticals, Inc, Basking \\ Ridge, NJ, USA
}

\begin{abstract}
Acromegaly is a rare disease most often caused by the prolonged secretion of excess growth hormone from a pituitary adenoma. The disease is associated with multiple significant comorbidities and increased mortality. The delay to diagnosis is often long. This may be because of low disease awareness among health care professionals, the insidious onset of differentiating features, and because patients are likely to present with complaints typical of other conditions more frequently seen in primary care. Early identification of acromegaly facilitates prompt treatment initiation and may minimize the permanent effects of excess growth hormone. The primary treatment for many patients will be pituitary surgery, although not all patients will be eligible for surgery or achieve a surgical cure. If biochemical control is not achieved following surgery, other treatment options include medical therapy and radiation therapy. Improved biochemical control may only alleviate rather than reverse the associated comorbidities. Thus, lifelong monitoring of patient health is needed, with particular attention to the management of cardiovascular risk factors. It is additionally important to consider the impact of both disease and treatment on patients' quality of life and minimize that impact where possible, but particularly for chronic therapies. For the majority of patients, chronic therapy is likely to include somatostatin analog injections. In some circumstances, it may be possible to extend the dosing interval of the analog once good biochemical control is achieved. Additional convenience may be gained from the possibility of self-/partner administration of treatment or administration of treatment by a health care professional at home. Overall, it is clear that the care of patients with acromegaly requires a highly coordinated approach involving numerous specialties (eg, endocrinology, surgery, cardiology). Further, patients' needs must be at the core of management and every effort must be made to improve health care experiences and minimize treatment burdens.
\end{abstract}

Keywords: acromegaly, diagnosis, treatment, quality of life, convenience

\section{Introduction}

Acromegaly results from the hypersecretion of growth hormone $(\mathrm{GH})$, usually by a pituitary tumor. ${ }^{1}$ The average age at diagnosis is 40 years, with an equal number of men and women affected. The disease is uncommon, although the exact prevalence is unclear; a recent review noted estimates of between 40 and 130 cases per million adults. $^{2}$ By comparison, in 2011, diabetes was estimated to affect $8.3 \%$ of adults (ie, 83,000 cases/million) aged over 20 years worldwide. ${ }^{3}$ A confirmed diagnosis of acromegaly commonly takes several years, ${ }^{4}$ leading to potentially serious consequences for patients' health and well-being. These delays may be due partly to the fact that many of the clinical features of acromegaly are nonspecific and similar to those seen
Correspondence: Daphne T Adelman Feinberg School of Medicine,

Northwestern University, 645 N Michigan Ave \#530, Chicago, IL 606II, USA

Tel +l 3129089002

Fax +I 3129268693

Email d-adelman@northwestern.edu 
with other conditions more often seen in primary care, such as hypertension or diabetes. The delay may also be because of the insidious onset of differentiating symptoms, such as acral enlargement.

The purpose of this article is to raise awareness and increase understanding of acromegaly symptoms and treatment. As patients with acromegaly present with many different comorbidities (particularly cardiovascular disease, diabetes, hypertension, sleep apnea, and arthropathy), increased awareness is needed across a broad spectrum of health care specialties. It is hoped that familiarity with acromegaly signs and symptoms will facilitate early diagnosis and treatment, and potentially affect mortality and morbidity rates positively. It is also important that health care professionals understand the impact the disease and its treatment have on patients so that they may ensure quality of life (QoL) is addressed as part of the overall patient management plan. In this article, we describe the symptoms, causes, and treatment options according to the current medical guidelines for acromegaly, ${ }^{5-7}$ then the factors affecting patients' QoL and acceptance of treatment.

\section{Understanding acromegaly and its treatment Pathophysiology and clinical presentation}

The pituitary gland, located just below the base of the brain (Figure 1), is responsible for secreting many hormones, including $\mathrm{GH}$, which is regulated via sophisticated feedback pathways. ${ }^{1}$ Acromegaly is most often due to the presence of a (generally benign) tumor in the pituitary gland. ${ }^{1}$ The tumor mass, depending on its size and location, may cause problems, such as vision loss due to compression of the optic chiasm. However, the tumor also secretes excess GH, resulting in increased secretion of insulin-like growth factor 1 (IGF-1). Excess GH and IGF-1 over a prolonged period are responsible for multiple significant comorbidities, including cardiovascular complications, cerebrovascular events, gonadal dysfunction, impaired glucose tolerance and diabetes, sleep apnea, impaired respiratory function, colonic neoplasms, and bone and joint diseases $^{5,6,8,9}$ (Figure 2). GH excess is also associated with an increased mortality rate, which is further elevated if comorbidities, particularly cardiovascular disease, are present. ${ }^{10}$ Specifically, mortality rates in untreated acromegaly are two to three times higher than those for the general population. Thus, early diagnosis and biochemical normalization are crucial in minimizing the permanent and life-limiting effects of excess GH.

\section{Diagnosing acromegaly}

Patients with longstanding disease commonly present at advanced stages with striking physical characteristics (eg, enlarged hands, feet, lips and tongue; prominent supraorbital ridges; and lower jaw protrusion) (Table 1). ${ }^{11}$ However, the onset of physical changes is insidious (Figure 3) and patients are unlikely to present with complaints relating directly to these distinguishing signs of acromegaly; ${ }^{5}$ rather, they are more likely to present with complaints typical
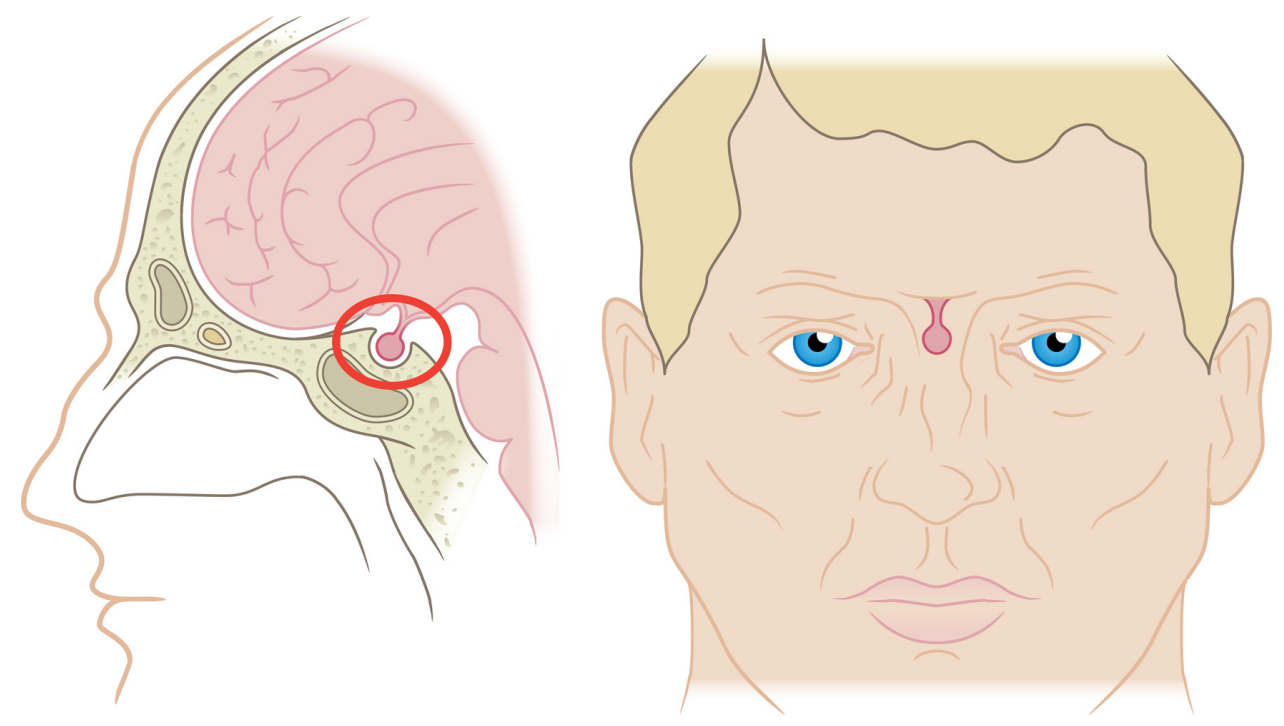

Figure I The pituitary gland.

Note: Reproduced with permission from Harris AG, Daly AF. Treatment of acromegaly. In: Acromegaly and Its Management. Philadelphia, PA: Lippincott-Raven; 1996:49-68. Copyright Lippincott Williams \& Wilkins, $1996 .{ }^{44}$ 


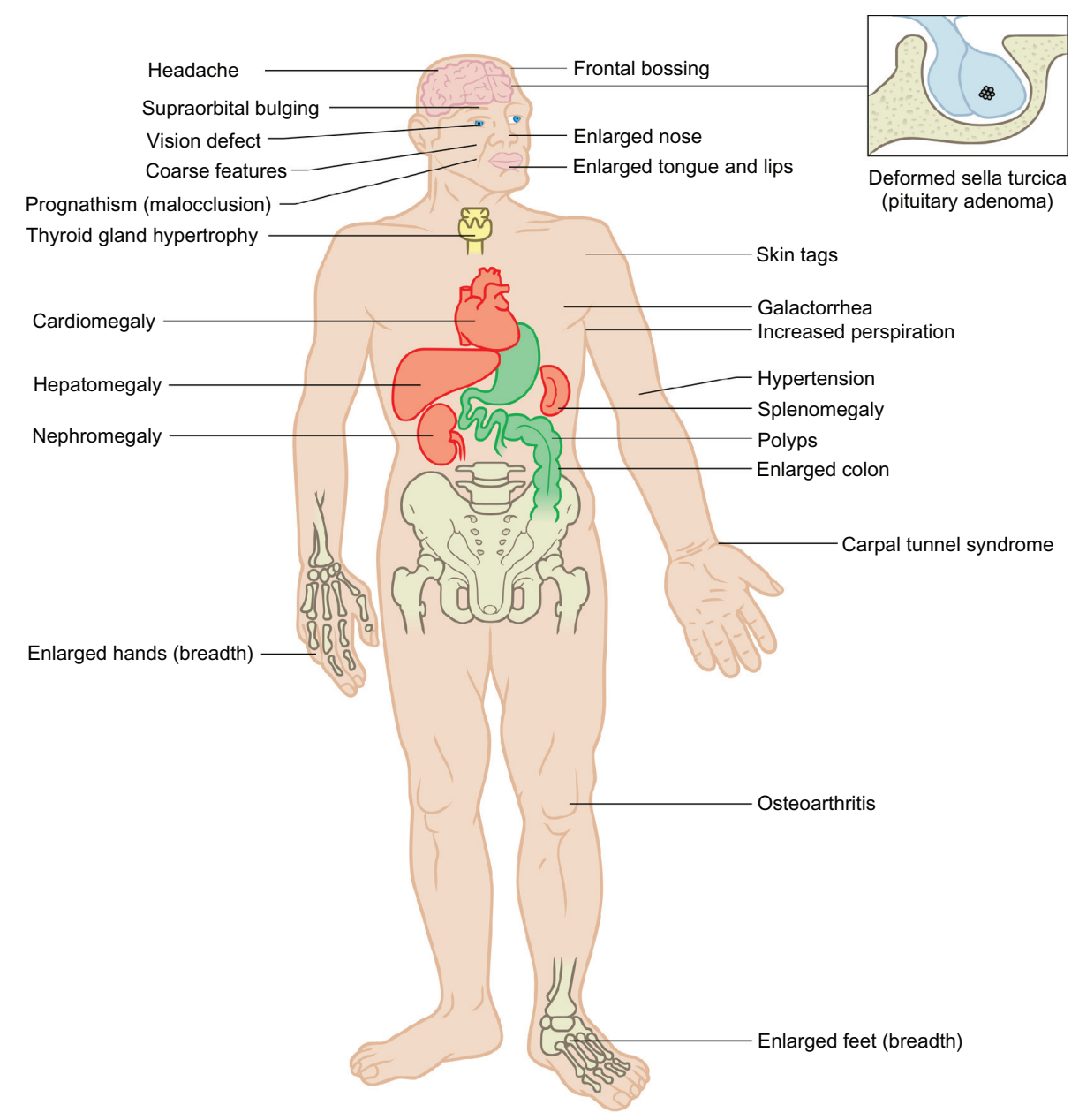

Figure 2 Signs and symptoms of acromegaly.

Note: Reproduced with permission from Harris AG, Daly AF. Treatment of acromegaly. In: Acromegaly and Its Management. Philadelphia, PA: Lippincott-Raven; 1996:49-68. Copyright Lippincott Williams \& Wilkins, 1996. ${ }^{44}$

of other conditions (eg, cardiovascular disease, diabetes, hypertension, and sleep apnea) more commonly seen in primary care.

Once acromegaly is suspected, biochemical testing, in combination with clinical findings, is needed for a diagnosis. ${ }^{5,6}$ Although GH levels are elevated in acromegaly, GH release is pulsatile, diurnal, and stimulated by exercise, stress, and sleep, ${ }^{6}$ such that a random GH level is of minimal diagnostic utility. Instead, acromegaly guidelines generally recommend an elevated IGF-1 level in combination with a failure to suppress $\mathrm{GH}$ levels to $<1 \mathrm{ng} / \mathrm{mL}$ in an oral glucose tolerance test as diagnostic criteria. ${ }^{5,6}$ Based on newer assays, a lower cutoff $(0.4 \mathrm{ng} / \mathrm{mL})$ on an oral glucose tolerance test would allow physicians to identify patients with mild GH hypersecretion. ${ }^{12}$ Radiological tests, such as a pituitary magnetic resonance imaging scan, should be performed to identify the presence of a tumor and evaluate its characteristics. ${ }^{5}$

\section{Treatment options}

The interrelated aims of treatment for acromegaly are to: control/reduce tumor size, normalize GH and IGF-1 levels, and improve comorbidities. ${ }^{5-7}$ These may all contribute to reductions in the mortality rate. Patients may receive as many as three different treatment modalities in an attempt to achieve these aims. Pituitary surgery is generally recommended as the primary treatment in patients with microadenomas (tumors $<1 \mathrm{~cm}$ ) and also in patients with macroadenomas (tumors $>1 \mathrm{~cm}$ ) that are associated with local mass effects or are enclosed and potentially curable surgically. ${ }^{5,7}$ Although transsphenoidal surgery, in which microsurgical instruments are passed through the nasal passage using either a microscope or an endoscope, is considered the safest route, there are nonetheless risks to be considered. These risks include, but are not limited to, bleeding, cerebrospinal fluid leaks, and pituitary gland damage with postoperative hormonal insufficiency. The severity 
Table I Clinical features with which patients most commonly present

\begin{tabular}{ll}
\hline Feature & Proportion of patients (\%) \\
\hline Acral enlargement & 86 \\
Maxillofacial changes & 74 \\
Excessive sweating & 48 \\
Arthralgias & 46 \\
Headache & 40 \\
Hypogonadal symptoms & 38 \\
Visual deficit & 26 \\
Fatigue & 26 \\
Weight gain & 18 \\
Galactorrhea & 9 \\
\hline
\end{tabular}

Note: Reproduced in part from Drange MR, Fram NR, Herman-Bonert V, Melmed S. Pituitary tumor registry: a novel clinical resource. J Clin Endocrinol Metab. 2000;85(I):168-174. Copyright The Endocrine Society 2000."

of these risks and the success of the operation are, however, highly dependent on the neurosurgeon's experience. Even with an experienced neurosurgeon, not all patients achieve a surgical cure. In a study documenting surgical outcomes from one center over a 19-year period, a cure (postoperative normalization of basal GH level, suppression of GH level to $<1 \mathrm{ng} / \mathrm{mL}$ during an oral glucose load, and normalization of IGF-1 level) was apparent in 57\% of 506 patients undergoing primary transsphenoidal surgery. ${ }^{13}$ Within this patient cohort, success rates were highest for those with microadenomas (75\%) or intrasellar macroadenomas

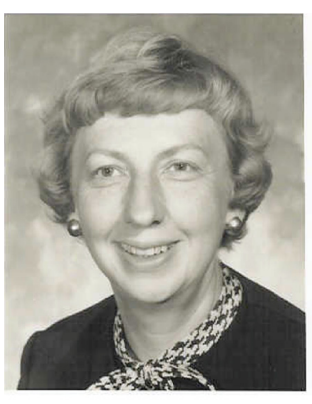

1977

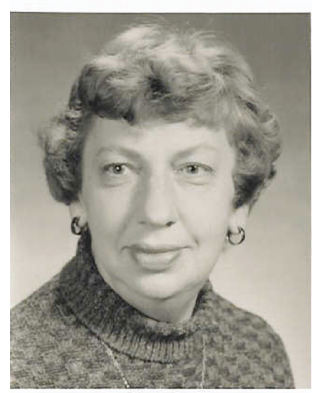

1983

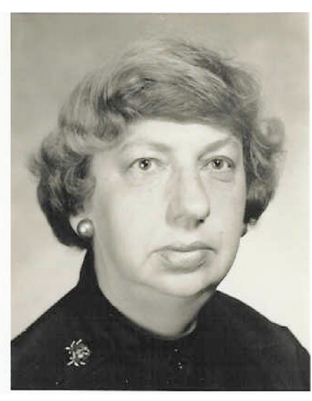

1981

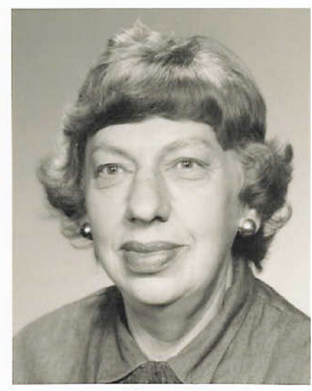

1988
Figure 3 Gradual change in facial features in acromegaly (prior to diagnosis). Note: This article was published in Molitch ME. Clinical manifestations of acromegaly. Endocrinol Metab Clin North Am. 1992;21(3):597-6I4. Copyright Elsevier 1992. ${ }^{45}$ (ie, macroadenomas localized within the immediate bony space) $(74 \%)$.

Medical therapy is appropriate for patients not achieving a surgical cure and for those for whom a surgical approach is not an option or who prefer medical therapy over surgery. ${ }^{5,7}$ Three classes of medical therapy are currently available: (1) somatostatin analogs, (2) GH-receptor antagonists, and (3) dopamine agonists. Two long-acting somatostatin analogs are currently widely available: a lanreotide formulation (known as Somatuline ${ }^{\circledR}$ Depot in the USA and Somatuline ${ }^{\circledR}$ Autoge $l^{\circledR}$ elsewhere; Ipsen Pharma Biotech, Signes, France $)^{14}$ and octreotide long-acting release (LAR) (Sandostatin ${ }^{\circledR}$ LAR; Novartis, East Hanover, NJ, USA). ${ }^{15}$ Lanreotide depot, which is provided in a 60,90 , or $120 \mathrm{mg}$ ready-touse, pre-filled syringe, does not require reconstitution and is administered by deep subcutaneous injection typically every 4 weeks. ${ }^{14}$ Patients well controlled on 60 or $90 \mathrm{mg}$, however, may be considered for extended dosing with $120 \mathrm{mg}$ every 6 to 8 weeks. ${ }^{14}$ Octreotide LAR, 10, 20, or $30 \mathrm{mg}$, requires reconstitution prior to administration and is injected intramuscularly every 4 weeks. ${ }^{15}$ Somatostatin analogs can provide effective biochemical control $1^{16,17}$ and may induce a reduction in tumor volume.$^{6}$ However, more than half of patients show either a partial or no biochemical response to somatostatin analogs, ${ }^{18}$ thus GH-receptor antagonist or dopamine agonist therapy as adjunct or alternative treatments may be required. ${ }^{5,7}$ Treatment with somatostatin analogs is generally well tolerated, although adverse effects may include transient abdominal pain and/or diarrhea, injectionsite reactions, gallstones and/or cholecystitis. ${ }^{14,15,17-19}$

The GH-receptor antagonist, pegvisomant $\left(\right.$ Somavert $^{\circledR}$; Pfizer Inc., New York, NY, USA), is supplied as a powder for reconstitution and is administered subcutaneously on a daily basis by patients/partners. ${ }^{20}$ Pegvisomant is effective in normalizing IGF-1 levels, ${ }^{5,7}$ and is indicated for patients with an inadequate response to or tolerability problems with somatostatin analogs. Pegvisomant may also be useful for improving glucose homeostasis in patients with associated diabetes. ${ }^{5,7}$ While treatment is generally well tolerated, patients may rarely experience flu-like illness and allergic reactions. Close monitoring of liver function is also recommended because of the possibility of increased levels of liver enzymes.

Two dopamine agonists, cabergoline and bromocriptine, are widely available, with the former considered more effective for acromegaly ${ }^{5,7}$ and better tolerated than the latter. ${ }^{5}$ Guidelines suggest dopamine agonists may be considered particularly in patients with mild biochemical 
activity $^{5,7}$ and that they may also be considered as first-line medical therapies because they are orally administered and less expensive than other medical therapies. ${ }^{5}$ Potential side effects with these agonists include gastrointestinal disturbance, orthostatic hypotension, headache, and nasal congestion. ${ }^{5,21,22}$

Radiation therapy may also be used, although it is generally reserved for patients in whom both surgical and medical interventions have not provided biochemical control. ${ }^{5,7}$ Stereotactic radiosurgery techniques have advantages over conventional fractionated radiotherapy, offering better targeting and reduced radiation exposure to surrounding tissue and shorter time to achieve control of IGF-1 and GH levels. ${ }^{23-26}$ Extremely large tumor volumes or tumors near the chiasm are not amenable to radiosurgery and such cases require fractionated radiotherapy. ${ }^{25}$ With either fractionated radiotherapy or radiosurgery, it may take many years to achieve the full therapeutic effect ${ }^{23}$ and continued medical treatment will usually be needed. Patients will also require serial pituitary function tests to assess for hypopituitarism resulting from radiation treatment. ${ }^{23}$

\section{Managing comorbidities}

A comprehensive review of studies conducted in patients with acromegaly indicates that biochemical control may alleviate but not necessarily reverse various key comorbidities of acromegaly. ${ }^{27}$ Of note are improvements in ventricular hypertrophy, hypertension, and hyperlipidemia; abnormalities of glucose metabolism; sleep apnea; and some skeletal system complications (carpal tunnel syndrome, joint space thickness, vertebral-fracture rate). These improvements notwithstanding, patients still require close monitoring throughout their lives. Aggressive management of hypertension and hyperlipidemia is of particular importance, with treatment goals aligned with those of high-risk cardiac patients. ${ }^{5}$ In addition, all patients should be tested for glucose intolerance or overt type 2 diabetes, and treated accordingly. ${ }^{5,7}$ The metabolic response to somatostatin analogs is variable and analog use may not be appropriate if glycemic control is adversely affected. ${ }^{28}$ Patients are also prone to respiratory complications and evaluations for sleep apnea in particular should be considered. ${ }^{8}$ Health screening for cancer should be performed, especially for colorectal cancer (due to a possible increase in premalignant colonic polyps). ${ }^{9}$ Patients often have skeletal and dental abnormalities that remain even if biochemical control is re-established, necessitating interventions by rheumatologists and maxillofacial surgeons. ${ }^{5}$

\section{Understanding the patient's perspective A severely impaired QoL}

Acromegaly is associated with reduced QoL, ${ }^{29,30}$ particularly in older patients. ${ }^{31}$ Impairments in QoL are probably not surprising given the impact on many areas of patients' lives of increased anxiety levels, ${ }^{32}$ the chronic nature of the disease, the burden of comorbidities, and, potentially, the burden of therapy. QoL in acromegaly is similar to that associated with osteoarthritis. ${ }^{29}$ Aspects that are particularly and severely affected are vitality and general health, ${ }^{29}$ as well as appearance, for which QoL scores are worse than for obese patients. ${ }^{30}$ Thus, it is not surprising that attention to $\mathrm{QoL}$ issues is advocated for patients with acromegaly. ${ }^{5}$

Improving patient QoL can be difficult. In part, this may be because achieving good biochemical control is not necessarily associated with a recovery in QoL. ${ }^{27,29,30}$ Clinical data suggest that the best QoL is associated with normalized IGF-1 levels and nadir GH levels during oral glucose tolerance tests of $0.3-1.0 \mu \mathrm{g} / \mathrm{L} .{ }^{31}$ Nonetheless, the continued impairments in QoL despite good biochemical control are probably due to the persistence of comorbidities, ${ }^{27,33}$ particularly arthropathy. ${ }^{34}$ Overall, as the effects of disease control and comorbidities on QoL are unclear, ${ }^{27}$ further investigation is warranted.

The effects of treatment on QoL can be complex..$^{31,35-37}$ Radiotherapy, in particular, has been associated with a negative effect on QoL. ${ }^{31}$ The negative effect may be a direct result of the radiation treatment itself or due to the decreased secretion of pituitary hormones following radiation treatment. ${ }^{31} \mathrm{GH}$ deficiency has certainly been linked with clinically relevant QoL impairments in patients in biochemical remission ${ }^{38}$ and there is some evidence that GH replacement therapy may help reverse this effect. ${ }^{39} \mathrm{~A}$ clinical study in patients with normalized IGF-1 concentrations during somatostatin analog treatment showed a significant QoL improvement (without a significant decrease in IGF-1 levels) after the addition of pegvisomant, $40 \mathrm{mg} /$ week. ${ }^{37}$ Treatment with a somatostatin analog alone may also have positive effects on QoL, but this has not been apparent in all studies ${ }^{35,40}$ and the findings are generally difficult to interpret.

\section{Ameliorating the treatment burden}

Careful consideration of how to minimize the impact of treatment on patients' daily lives is important, particularly for chronic therapies. For the majority of patients with acromegaly, long-term medical therapy is likely to be with a somatostatin analog. The first improvement in the convenience of these analogs was the appearance of longer-acting 
formulations that facilitated a reduction from many to just one injection per month. (As discussed earlier, this dosing interval may be further extended to every 6-8 weeks for patients who have achieved good biochemical control with lanreotide depot. ${ }^{14}$ ) For octreotide LAR, patient convenience may be improved in cases where nurses can make home visits to administer injections. ${ }^{41}$ The possibility of self-/partner administration with lanreotide depot may also help to minimize the treatment burden for some patients. In a US single-arm open-label study, out of the 33 patients previously using octreotide LAR who switched to self-/partner administration with lanreotide depot, 38\% reported that octreotide LAR had been "somewhat"/“very convenient" to use, compared with $91 \%$ reporting the same for lanreotide depot. ${ }^{42}$ Most $(81 \%)$ of these 33 patients preferred lanreotide depot over octreotide LAR. ${ }^{42}$ Data for this group indicated that, to receive each octreotide LAR injection, $80 \%$ of patients had spent at least 1 hour

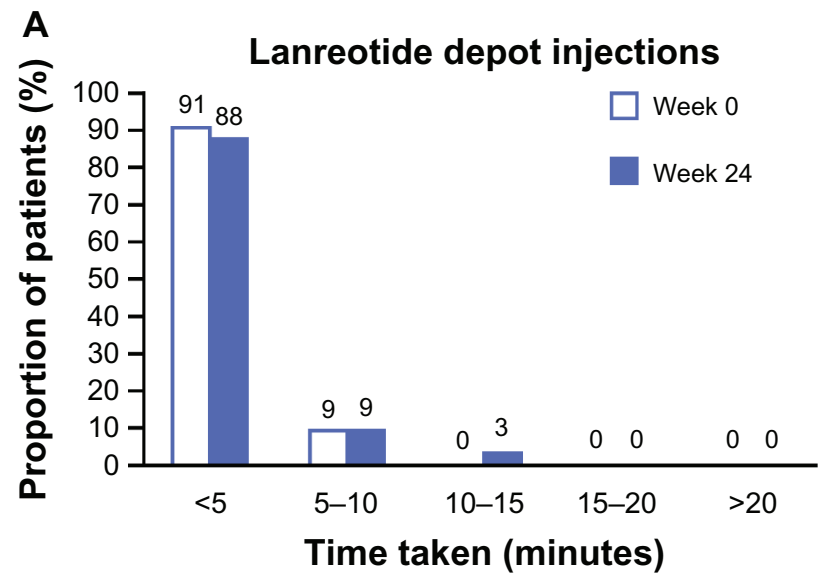

traveling to and from and/or waiting at the clinic; for $17 \%$ of patients, the distance traveled exceeded 100 miles (Figure 4) (Ipsen, unpublished data, 2009). In contrast, self-/partner administration of the lanreotide depot injection took less than 5 minutes for $88 \%$ of patients (Figure 4 ) (Ipsen, unpublished data, 2009).

Some patients will receive a dopamine agonist or GHreceptor antagonist rather than somatostatin analogs on a long-term basis. In terms of convenience, a dopamine agonist is likely to be well accepted by patients because it is an oral medication. In contrast, the GH-receptor antagonist is an injectable therapy recommended for daily use. However, it can be injected by patients/caregivers and some research suggests that patients on stable daily doses could be switched to once- or twice-weekly doses (so that the seven injections are administered together on 1 day in the week, or spread over 2 days in the week); this appears to have been well received by patients. ${ }^{43}$

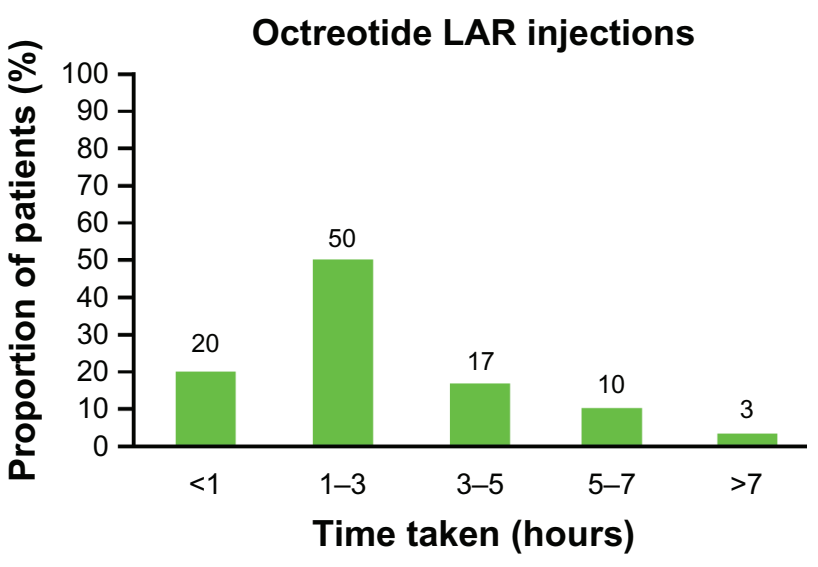

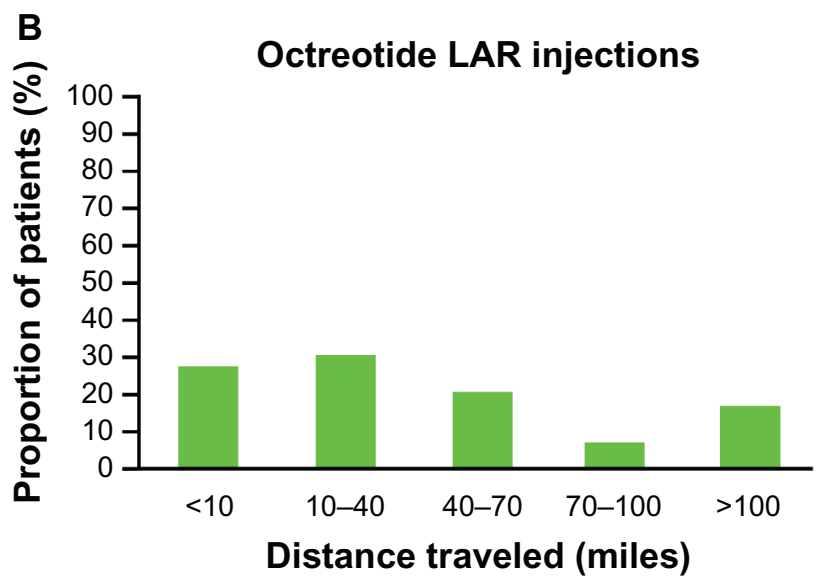

Figure 4 (A) Time associated with lanreotide depot ${ }^{\mathrm{a}}$ and octreotide long-acting release (LAR) injections and (B) distance traveled to clinic for an octreotide LAR injection. Notes: Data are for 33 patients switching from previous octreotide LAR injections in a prospective open-label 24-week study conducted in the USA (lpsen, unpublished data, 2009). Patients completed a questionnaire at week 0 related to the convenience of the previous octreotide LAR injections received from a health care professional. Patients opting to self-/partner administer lanreotide depot injections were instructed on injection technique by a health care professional at week 0 , but patients/partners administered all study injections themselves (once every 28 days). Patients completed convenience questions relating to lanreotide at weeks 0 and 24 . ${ }^{\text {SSomatuline }}{ }^{\circledR}$ depot is known as Somatuline ${ }^{\circledast}$ Autogel $^{\circledast}$ (Ipsen Pharma Biotech, Signes, France) outside the USA. 


\section{Conclusion}

Acromegaly is a serious condition, associated with multiple comorbidities and increased mortality. The delay to diagnosis is often long. This is probably due to low disease awareness among health care professionals, the insidious onset of differentiating features, and because patients are likely to present with complaints typical of other conditions more frequently seen in primary care. Early identification of the signs and symptoms of the disease by health care professionals knowledgeable about acromegaly may help to mitigate this delay. Treatment can then be initiated promptly, with the potential to reduce mortality.

For the patient, both the disease and the treatment burden are immense. More than one treatment modality is often necessary and medical therapy is commonly needed on a long-term basis. Comorbidities, particularly those of a cardiovascular nature, may also require immediate attention. Even with successful control of the underlying hormonal abnormalities, various comorbidities will persist, necessitating additional long-term monitoring and treatment. It is clear that the care of these patients requires a highly coordinated multidisciplinary approach. It is also clear that any disease management strategy must put patients' needs at its core, with every effort made to improve the health care experiences of patients and minimize their treatment burden.

\section{Acknowledgments}

The authors accept direct responsibility for this paper and are grateful for the contribution made by Watermeadow Medical (supported by Ipsen) to the development of the outline and first draft, and in collating comments for subsequent drafts.

\section{Disclosure}

Daphne T Adelman has acted as a consultant for Pfizer and Ipsen and served on a speakers' bureau for Ipsen. Karen JP Liebert has received research support from Pfizer. Lisa B Nachtigall has received support from Ipsen for consultation and research. Michele Lamerson and Bert Bakker were employees of Ipsen Biopharmaceuticals, Inc.

\section{References}

1. Melmed S. Medical progress: acromegaly. N Engl J Med. 2006;355(24): 2558-2573.

2. Chanson P, Salenave S, Kamenicky P, Cazabat L, Young J. Pituitary tumours: acromegaly. Best Pract Res Clin Endocrinol Metab. 2009; 23(5):555-574.

3. International Diabetes Federation (IDF). IDF Diabetes Atlas, 5th ed. Brussels: IDF; 2011.

4. Nachtigall L, Delgado A, Swearingen B, Lee H, Zerikly R, Klibanski A. Changing patterns in diagnosis and therapy of acromegaly over two decades. J Clin Endocrinol Metab. 2008;93(6):2035-2041.
5. Katznelson L, Atkinson JL, Cook DM, Ezzat SZ, Hamrahian AH, Miller KK; American Association of Clinical Endocrinologists. American Association of Clinical Endocrinologists medical guidelines for clinical practice for the diagnosis and treatment of acromegaly -2011 update. Endocr Pract. 2011;17 Suppl 4:1-44.

6. Giustina A, Chanson P, Bronstein MD, et al; Acromegaly Consensus Group. A consensus on criteria for cure of acromegaly. $J$ Clin Endocrinol Metab. 2010;95(7):3141-3148.

7. Melmed S, Colao A, Barkan A, et al; Acromegaly Consensus Group. Guidelines for acromegaly management: an update. J Clin Endocrinol Metab. 2009;94(5):1509-1517.

8. Davi' MV, Dalle Carbonare L, Giustina A, et al. Sleep apnoea syndrome is highly prevalent in acromegaly and only partially reversible after biochemical control of the disease. Eur J Endocrinol. 2008;159(5): 533-540.

9. Rokkas T, Pistiolas D, Sechopoulos P, Margantinis G, Koukoulis G. Risk of colorectal neoplasm in patients with acromegaly: a metaanalysis. World J Gastroenterol. 2008;14(22):3484-3489.

10. Sherlock M, Ayuk J, Tomlinson JW, et al. Mortality in patients with pituitary disease. Endocr Rev. 2010;31(3):301-342.

11. Drange MR, Fram NR, Herman-Bonert V, Melmed S. Pituitary tumor registry: a novel clinical resource. J Clin Endocrinol Metab. 2000;85(1): 168-174.

12. Freda PU, Reyes CM, Nuruzzaman AT, Sundeen RE, Bruce JN. Basal and glucose-suppressed GH levels less than $1 \mathrm{microg} / \mathrm{L}$ in newly diagnosed acromegaly. Pituitary. 2003;6(4):175-180.

13. Nomikos P, Buchfelder M, Fahlbusch R. The outcome of surgery in 668 patients with acromegaly using current criteria of biochemical “cure." Eur J Endocrinol. 2005;152(3):379-387.

14. Ipsen. Somatuline ${ }^{\circledR}$ Depot [prescribing information]. Silver Spring, MD US Food and Drug Administration (FDA); 2011. Available from: http:// www.accessdata.fda.gov/drugsatfda_docs/label/2011/022074s003lbl. pdf. Accessed September 28, 2012.

15. Novartis. Sandostatin ${ }^{\circledR}$ LAR Depot [prescribing information]. Silver Spring, MD: FDA; 2011. Available from: http://www.accessdata. fda.gov/drugsatfda_docs/label/2011/021008s025lbl.pdf. Accessed September 28, 2012.

16. Maiza JC, Vezzosi D, Matta M, et al. Long-term (up to 18 years) effects on GH/IGF-1 hypersecretion and tumour size of primary somatostatin analogue (SSTa) therapy in patients with GH-secreting pituitary adenoma responsive to SSTa. Clin Endocrinol (Oxf). 2007;67(2): 282-289.

17. Caron P, Cogne M, Raingeard I, Bex-Bachellerie V, Kuhn JM. Effectiveness and tolerability of 3-year lanreotide Autogel treatment in patients with acromegaly. Clin Endocrinol. 2006;64(2):209-214.

18. Mercado M, Borges F, Bouterfa H, et al; SMS995B2401 Study Group. A prospective, multicentre study to investigate the efficacy, safety and tolerability of octreotide LAR (long-acting repeatable octreotide) in the primary therapy of patients with acromegaly. Clin Endocrinol. 2007;66(6):859-868.

19. Murray RD, Melmed S. A critical analysis of clinically available somatostatin analog formulations for therapy of acromegaly. $J$ Clin Endocrinol Metab. 2008;93(8):2957-2968.

20. Pzifer. Somavert ${ }^{\mathbb{1}}$ [prescribing information]. Silver Spring, MD: FDA; 2012. Available from: http://www.accessdata.fda.gov/drugsatfda_docs/ label/2012/021106s031lbl.pdf. Accessed September 28, 2012.

21. Novartis. Parlodel ${ }^{\circledR}$ [prescribing information]. Silver Spring, MD: FDA; 2012. Available from: http://www.accessdata.fda.gov/drugsatfda_docs label/2012/017962s065s068lbl.pdf. Accessed September 28, 2012.

22. Pfizer. Dostine $x^{\circledR}$ [prescribing information]. Silver Spring, MD: FDA; 2011. Available from: http://www.accessdata.fda.gov/drugsatfda_docs/ label/2011/020664s012lbl.pdf. Accessed September 28, 2012.

23. Loeffler JS, Shih HA. Radiation therapy in the management of pituitary adenomas. J Clin Endocrinol Metab. 2011;96(7):1992-2003.

24. Petit JH, Biller BM, Coen JJ, et al. Proton stereotactic radiosurgery in management of persistent acromegaly. Endocr Pract. 2007;13(7): 726-734. 
25. Jagannathan J, Sheehan JP, Pouratian N, Laws ER Jr, Steiner L, Vance ML. Gamma knife radiosurgery for acromegaly: outcomes after failed transsphenoidal surgery. Neurosurgery. 2008;62(6):1262-1269; discussion 1262-1269.

26. Pollock BE, Jacob JT, Brown PD, Nippoldt TB. Radiosurgery of growth hormone-producing pituitary adenomas: factors associated with biochemical remission. J Neurosurg. 2007;106(5):833-838.

27. Ben-Shlomo A, Sheppard MC, Stephens JM, Pulgar S, Melmed S. Clinical, quality of life, and economic value of acromegaly disease control. Pituitary. 2011;14(3):284-294.

28. Mazziotti G, Floriani I, Bonadonna S, Torri V, Chanson P, Giustina A. Effects of somatostatin analogs on glucose homeostasis: a metaanalysis of acromegaly studies. J Clin Endocrinol Metab. 2009;94(5): 1500-1508.

29. Rowles SV, Prieto L, Badia X, Shalet SM, Webb SM, Trainer PJ. Quality of life (QOL) in patients with acromegaly is severely impaired: use of a novel measure of QOL: acromegaly quality of life questionnaire. J Clin Endocrinol Metab. 2005;90(6):3337-3341.

30. Webb SM, Badia X, Surinach NL; Spanish AcroQoL Study Group. Validity and clinical applicability of the acromegaly quality of life questionnaire, AcroQoL: a 6-month prospective study. Eur J Endocrinol. 2006;155(2):269-277.

31. Kauppinen-Mäkelin R, Sane T, Sintonen H, et al. Quality of life in treated patients with acromegaly. J Clin Endocrinol Metab. 2006; 91(10):3891-3896.

32. Sievers C, Ising M, Pfister H, et al. Personality in patients with pituitary adenomas is characterized by increased anxiety-related traits: comparison of 70 acromegalic patients with patients with nonfunctioning pituitary adenomas and age- and gender-matched controls. Eur J Endocrinol. 2009;160(3):367-373.

33. Biermasz NR, Pereira AM, Smit JW, Romijn JA, Roelfsema F. Morbidity after long-term remission for acromegaly: persisting jointrelated complaints cause reduced quality of life. J Clin Endocrinol Metab. 2005;90(5):2731-2739.

34. Wassenaar MJ, Biermasz NR, Kloppenburg M, et al. Clinical osteoarthritis predicts physical and psychological QoL in acromegaly patients. Growth Horm IGF Res. 2010;20(3):226-233.
35. Lombardi G, Minuto F, Tamburrano G, et al. Efficacy of the new longacting formulation of lanreotide (lanreotide Autogel) in somatostatin analogue-naive patients with acromegaly. J Endrocrinol Invest. 2009; 32(3):202-209.

36. Ghigo E, Biller BM, Colao A, et al. Comparison of pegvisomant and long-acting octreotide in patients with acromegaly naïve to radiation and medical therapy. J Endocrinol Invest. 2009;32(11):924-933.

37. Neggers SJ, van Aken MO, de Herder WW, et al. Quality of life in acromegalic patients during long-term somatostatin analog treatment with and without pegvisomant. J Clin Endocrinol Metab. 2008;93(10): 3853-3859.

38. Wexler T, Gunnell L, Omer Z, et al. Growth hormone deficiency is associated with decreased quality of life in patients with prior acromegaly. J Clin Endocrinol Metab. 2009;94(7):2471-2477.

39. Miller KM, Wexler T, Fazeli P, et al. Growth hormone deficiency after treatment of acromegaly: a randomized, placebo-controlled study of growth hormone replacement. J Clin Endocrinol Metab. 2010;95(2): 567-577.

40. Hua SC, Yan YH, Chang TC. Associations of remission status and lanreotide treatment with quality of life in patients with treated acromegaly. Eur J Endocrinol. 2006;155(6):831-837.

41. Novartis. Sandostatin ${ }^{\circledR}$ LAR Depot: nurse home injection program (NHIP) for eligible patients with acromegaly [web page on the Internet]. East Hanover, NJ: Novartis; nd. Available from: http://www. us.sandostatin.com/patient/disease/acromegaly/nhip.jsp. Accessed November 15, 2012.

42. Salvatori R, Nachtigall LB, Cook DM, et al; SALSA Study Group. Effectiveness of self- or partner-administration of an extended-release aqueous-gel formulation of lanreotide in lanreotide-naïve patients with acromegaly. Pituitary. 2010;13(2):115-122.

43. Higham CE, Thomas JD, Bidlingmaier M, Drake WM, Trainer PJ. Successful use of weekly pegvisomant administration in patients with acromegaly. Eur J Endocrinol. 2009;161(1):21-25.

44. Harris AG, Daly AF. Treatment of acromegaly. In: Acromegaly and its management. Philadelphia, PA: Lippincott-Raven; 1996:49-68.

45. Molitch ME. Clinical manifestations of acromegaly. Endocrinol Metab Clin North Am. 1992;21(3):597-614.
International Journal of General Medicine

\section{Publish your work in this journal}

The International Journal of General Medicine is an international, peer-reviewed open-access journal that focuses on general and internal medicine, pathogenesis, epidemiology, diagnosis, monitoring and treatment protocols. The journal is characterized by the rapid reporting of reviews, original research and clinical studies across all disease areas.

\section{Dovepress}

A key focus is the elucidation of disease processes and management protocols resulting in improved outcomes for the patient.The manuscript management system is completely online and includes a very quick and fair peer-review system. Visit http://www.dovepress.com/ testimonials.php to read real quotes from published authors. 